\title{
TERCEIRIZAÇÃO DO TRABALHO DOCENTE À LUZ DA RESPONSABILIDADE SOCIAL DA EDUCAÇÃO SUPERIOR
}

\author{
OUTSOURCING EDUCATOR WORK UNDER THE LIGHT OF THE SOCIAL RESPONSIBILITY \\ OF HIGHER EDUCATION
}

\author{
Adolfo Ignacio Calderón ${ }^{1}$
}

Resumo $\mathrm{O}$ artigo apresenta a discussão da compreensão da terceirização do trabalho docente no ensino superior privado, realizado por meio de cooperativas de mão de obra, à luz da responsabilidade social da educação superior. Conceitualiza a responsabilidade social, privilegiando duas abordagens: a normativa, de ordem legal, e a ética, direcionada ao desenvolvimento humano. Examina a coerência ética que deve existir na gestão universitária no equacionamento das exigências de maximização de recursos visando a ganhos de competitividade, com os princípios e valores que deveriam nortear os empreendimentos educacionais dentro de um cenário marcado pelas exigências e demandas do Estado e da sociedade por uma maior responsabilidade social da educação superior, principalmente do setor privado.

Palavras-chave responsabilidade social universitária; trabalho docente; ensino superior privado; gestão universitária; terceirização.
Abstract This article focuses on understanding the outsourcing of teaching in private higher education, carried out by means of labor cooperatives, under the light of the social responsibility of higher education. It conceptualizes social responsibility by focusing on two approaches: normative, which is legal in nature, and the ethical, which is directed to human development. The author examines the ethical coherence there must be in the university management process when addressing the requirements of maximizing resources aimed at gains in competitiveness, with the principles and values that should guide the educational endeavors within a scenario marked by the requirements and demands of the State and of society for the increased social responsibility of higher education, especially in the private sector.

Keywords university social responsibility; teaching; private higher education; university management; outsourcing. 


\section{Observações preliminares}

Com a institucionalização, no Brasil, do mercado de educação superior, na década de 1990, configurou-se um cenário altamente mercantilizado, heterogêneo e diversificado em termos de instituições e serviços educacionais, em que se destacam, pelo elevado volume de alunos, as grandes instituições de massa.

Existem diversos tipos de mercados, com as mais variadas características, dependendo das regiões do país. Os mais preocupantes são aqueles que, aproveitando a lentidão e, em muitos casos, a omissão do Estado, adotam práticas transgressoras da lei, visando não somente ao aumento dos lucros, mas também a superar sérios problemas operacionais como o elevado número de vagas ociosas, a inadimplência, elevados impostos e encargos sociais, pagamentos de empréstimos e a necessidade de manter o equilíbrio financeiro da instituição.

Apesar da heterogeneidade do segmento do ensino superior privado, no qual convivem as instituições de ensino superior (IES) com fins lucrativos e as instituições filantrópicas, comunitárias e as de natureza confessional, o pragmatismo econômico na gestão universitária com o objetivo de garantir a saúde financeira e, em muitos casos, a sobrevivência institucional, tornou-se uma tendência hegemônica no âmbito universitário.

As diversas instituições privadas ficaram em um mesmo patamar como empreendimentos empresariais que precisam aprimorar continuamente suas estruturas gerenciais visando a concorrer e a obter um bom desempenho no mercado para garantir seu financiamento.

No contexto das IES do setor privado, o exercício da função docente, na forma de professor horista, tende a se tornar cada vez mais precário e instável. O professor faz parte de um sistema contratual em que predomina o pagamento pelo número de horas de aula ministradas, sem tempo para o desenvolvimento de pesquisa ou para uma dedicação maior às atividades pedagógicas. Com isto, vê-se obrigado a exercer a docência em mais de uma instituição para sobreviver às flutuações semestrais da sua carga horária de trabalho, definida com base no número de alunos matriculados a cada semestre.

É precisamente no âmbito do trabalho docente, marcado pela existência de recursos humanos precarizados, em que surgem novos modelos contratuais, comprovadamente voltados a burlar as leis trabalhistas, visando a reduzir os custos operacionais das instituições particulares.

Fazemos referência à terceirização do trabalho docente por meio de cooperativas de mão de obra, que ganharam visibilidade na mídia na metade da primeira década do século XXI. Neste sistema, o professor recebe um pagamento maior pela hora de trabalho, mas, em contrapartida, não recebe nenhum benefício social ou trabalhista. Trata-se de um sistema que se 
sustenta na violação dos princípios fundamentais do cooperativismo, sendo o principal a livre adesão, uma vez que, para trabalhar, o professor é coagido a se associar a uma cooperativa (Calderón e Lourenço, 2011).

É explícita a relação mercantil que se estabelece entre o professor e a instituição de ensino. A teoria de Marx sobre o processo de trabalho, expressa na sua obra-prima, $O$ capital, ganha atualidade e vigência quando aplicada à compreensão do trabalho docente. Para ele, o trabalho "é um processo, entre coisas que o capitalista comprou, entre coisas que lhe pertencem", enquadrando-se nessas coisas a mercadoria força de trabalho vendida pelo professor (Marx, 1996, p. 304). Sem entrar na questão da exploração do trabalho a partir do valor agregado não repassado ao trabalhador, chama a atenção a exploração sem limites do trabalho docente, por parte dos capitalistas da educação, que agem, retomando as palavras metafóricas de Marx (1996, p. 347) "à maneira dos vampiros, chupando trabalho vivo e que vive tanto mais quanto mais trabalho vivo chupa".

De forma paralela assiste-se, desde 2004, a cobranças por parte do Estado por maior Responsabilidade Social da Educação Superior (RSES), tanto das IES estatais como as do setor privado. A cobrança ganhou status de lei, ao incorporar a responsabilidade social como uma categoria de avaliação institucional no Sistema Nacional de Avaliação da Educação Superior (Sinaes).

Neste artigo, 2 pretendemos analisar, a partir de uma pesquisa bibliográfica, as condições do trabalho docente no âmbito das cooperativas de mão de obra à luz da RSES, privilegiando duas abordagens. A primeira é normativa, de ordem legal. Já a segunda é de ordem ética. Defende-se, teoricamente, a coerência ética que deve existir na gestão universitária no equacionamento das exigências de maximização de recursos visando a ganhos de competitividade, com os princípios e valores que deveriam nortear os empreendimentos educacionais dentro de um cenário marcado pelas exigências e demandas do Estado e da sociedade por uma maior RSES, principalmente das IES do setor privado.

\section{As cooperativas de mão de obra à luz da literatura científica}

A contratação de professores por meio de cooperativas de mão de obra é uma nova forma contratual que emergiu nas regiões do país onde existem mercados educacionais altamente competitivos. Por meio delas, o professor universitário se torna um profissional autônomo e completamente desamparado pela legislação trabalhista disciplinada pela Consolidação das Leis do Trabalho (CLT).

Por ser uma modalidade contratual marcada pelo questionamento sobre sua legalidade, não há dados oficiais sobre o número de professores 
cooperativados, mas os divulgados pela Federação das Cooperativas Educacionais de São Paulo apontam a existência de 15 mil professores somente no estado de São Paulo (Takahashi, 2006).

Neste sistema de trabalho, os professores são transformados em trabalhadores autônomos, empreendedores, supostos sócios da cooperativa, uma vez que não possuem vínculo empregatício com a cooperativa de trabalho nem com a IES em que lecionam.

Assim, assiste-se a uma mudança paradigmática, fortalecendo a ideia de professor empreendedor, do profissional da educação que presta serviços de forma autônoma e que possui conhecimentos e habilidades vendidas no mercado.

Dessa ideia depreende-se outra: a de profissional 'liberal', o professor-empreendedor que, para valorizar seu trabalho, deve investir em seu próprio aprimoramento, fato que cotizaria seus serviços oferecidos ao mercado.

A ideia de professor-profissional liberal e professor-empreendedor que, na condição de empresário de seu próprio conhecimento, emite uma nota fiscal pelos serviços prestados, típico de uma lógica liberal de mercado, colide diretamente com a visão ainda predominante do professor como trabalhador protegido pela legislação trabalhista, herança do Estado social ou intervencionista, resultado de lutas históricas dos trabalhadores.

No sistema cooperativo, a contratação deste professor se dá pelo regime 'horista', porém com uma importante diferença, o pagamento restringe-se às aulas ministradas sem direito a licenças, férias, $13^{\circ}$ salário e outros benefícios legalmente assegurados. Está-se diante do professor sem vínculo empregatício com a instituição educacional em que atua, embora existam elementos explícitos que configuram situação de emprego, como exemplo, a subordinação à estrutura universitária. O depoimento de um professor cooperativado ilustra bem a situação:

Eu estudo de domingo a domingo. O investimento é alto. E esse investimento tem que ter um retorno: tendo carteira assinada, tendo todos os meus direitos, até porque é uma questão de cidadania, enquanto trabalhador. (...) Mas, dentro da cooperativa isso não existe (...) A gente se sente como escravos. Nesse sistema você não tem seus direitos, só terá seus direitos se você for atrás. É um trabalho escravista ainda. Se eu for atrás, se eu lutar, se eu for ao Ministério do Trabalho, se eu for com um advogado, eu tenho esse direito... mas até então, não tenho (Calderón et al., 2008b, p. 203). ${ }^{3}$

Assim, o grande diferencial em relação aos professores 'horistas' contratados via CLT é a ausência de direitos do trabalhador, direitos considerados de cidadania, com a suposta vantagem de receberem, por hora/aula trabalhada, um valor considerado acima do mercado. Atualmente algumas 
IES que experimentaram a adoção desse modelo gerencial estão pagando pelas consequências dessa aventura contratual. O modelo se mostrou inviável, uma vez que o Ministério Público do Trabalho (MPT) e a Justiça do Trabalho o têm enquadrado no marco da ilegalidade, gerando severas punições para as IES que o adotaram.

Pesquisas demonstraram que a posição dos sindicatos de professores é única e homogênea: a maioria das cooperativas age objetivando fraudar a legislação trabalhista, os direitos do trabalhador e os princípios cooperativistas (Calderón et al., 2008a). Por sua vez, a postura dos magistrados também tem sido muito clara quando se refere a esse tipo de atuação das cooperativas na educação superior, ressaltando-se a fraude trabalhista e o desvirtuamento dos princípios do cooperativismo. Nessa mesma linha tem se posicionado o MPT. Nos casos em que a Justiça teve que se manifestar, constata-se a rigidez com que vem punindo as IES, visando a coibir esse modelo gerencial.

A contratação de professores por meio de cooperativas passou de panaceia para reduzir custos a uma prática gerencial que não somente infringe a lei, mas também coloca em risco a busca permanente pela qualidade do ensino como desafio da RSES.

Segundo uma pesquisa de natureza qualitativa sobre o exercício da docência por meio de cooperativas, baseada na análise de conteúdo de dez entrevistas realizadas com professores universitários cooperados que atuam em quatro IES privadas do estado de São Paulo, existem, na condição de cooperativados, professores com os mais diversos títulos acadêmicos e com uma heterogênea experiência no campo da docência. Ou seja, não é uma relação contratual restrita a professores que estão iniciando a carreira acadêmica (Calderón et al., 2008b).

De acordo com essa pesquisa, o principal motivo pelo qual os professores aceitam trabalhar nessa modalidade contratual é a necessidade financeira. A motivação sustenta-se em um discurso pautado em dois fatos: a necessidade de sobrevivência familiar e a falta de opção no mercado de educação superior. Nas entrevistas realizadas, emergiu a imagem do docente universitário, especialista, mestre ou doutor, que como trabalhador tem de sustentar sua família e também sofre as consequências psicológicas e financeiras do desemprego, procurando meios de fugir dessa realidade (Calderón et al. 2008b).

Nesse discurso da necessidade financeira, ganha maior ênfase a falta de opção em termos empregatícios, que remete à submissão a um determinado regime contratual diante da dificuldade de inserção no mercado de trabalho regulamentado pelas normas da CLT.

Outro dado importante, apresentado pela pesquisa, diz respeito à existência, entre os professores, de uma insatisfação generalizada diante do referido 
modelo contratual com base na ausência dos direitos trabalhistas. Os depoimentos revelam sentimentos ambíguos no que se refere à relação docente-regime contratual. De um lado, o prazer de trabalhar em sala de aula; de outro, desânimo, desmotivação, desvalorização e precarização da função docente. Como reflexo dessa insatisfação, as entrevistas mostram também a existência de uma atitude permanente de atenção e de expectativa diante de novas oportunidades de emprego com melhores condições de trabalho.

Quanto aos prejuízos que esse tipo de contratação pode causar em sala de aula, segundo os informantes, os prejuízos atingem diretamente a motivação do professor, impossibilitando o compromisso e o envolvimento profissional do docente com a instituição educacional, colocando em risco a relação ensino-aprendizagem.

Entretanto, constata-se, no discurso da maioria dos professores, uma dicotomia no exercício da docência. Há um conflito entre o compromisso ético em relação aos alunos e a realidade trabalhista. Por um lado, os ideais em relação ao papel social do docente, ideais que, como diz Ferreira (2007), estão estreitamente vinculados com a formação humana e, por outro, um cotidiano laboral marcado pela exploração profissional, desvalorização do professor, ausência de direitos trabalhistas e fragilização da autoestima do docente. O depoimento a seguir de um professor cooperativo é ilustrativo:

Quando um professor entra em sala de aula, deixa ou deveria deixar de fora os problemas e insatisfações. Nosso aluno não pode ser punido por não estarmos satisfeitos com a política de valorização docente. Ensinar e aprender é o nosso objetivo e deve ser cumprido a qualquer custo, desde o momento que aceitamos e assumimos a contratação. Por mais que tivesse consciência do compromisso com o aluno, ficou difícil manter a motivação. Todos os problemas trazidos pelo regime de cooperativas seriam menos graves, se associado a ele não viesse um modelo de gestão que desconsidera o ser humano, que cada profissional da educação é (Calderón et al., 2008a, p. 207).

De acordo com os resultados da pesquisa, a contratação por meio de cooperativas coloca em risco a relação ensino-aprendizagem em decorrência da fragilização do compromisso ético com a formação dos alunos.

Convém ressaltar que, no exercício da docência, há um componente de subjetividade muito grande. O professor pode quebrar ou não o compromisso ético com a formação do aluno. Diante disso, não devem causar surpresa os resultados positivos que algumas IES possam obter nas avaliações do Ministério da Educação em relação ao desempenho de alunos, apesar de terem sido formados por professores cooperativados. O modelo contratual acentua o risco, mas não significa que o professor necessariamente quebrará o compromisso ético. A pesquisa mostra que haverá prejuízos sempre que 
os professores quebrem seu compromisso ético com a formação dos alunos diante da precariedade da relação contratual, ficando um risco em aberto.

Como se pode observar, além de colocar em risco o processo de aprendizagem dos alunos, verifica-se a existência de um cenário que contrasta com os princípios básicos da gestão das organizações, como é a necessidade de manter um corpo de funcionários satisfeitos e estimulados com o trabalho e com a política de recursos humanos da organização em que atuam.

\section{As cooperativas de mão de obra à luz da RSES}

O termo responsabilidade social pode ser considerado, sem dúvida alguma, o grande 'osso' na garganta dos gestores, pesquisadores e intelectuais que lidam com a gestão universitária, mais especificamente, com a extensão universitária.

Ainda hoje existe grande resistência na utilização do termo responsabilidade social, preferindo-se usar compromisso social. Sem dúvida alguma, isso é reflexo da perplexidade causada pelo governo federal ao incorporar na legislação o termo responsabilidade social, considerado, por muitos, procedente do universo empresarial, distante da nossa tradição universitária. Por que motivos o governo federal decidiu impor, na lei do Sinaes, o termo responsabilidade social, uma palavra que estava na 'crista da onda' do mundo empresarial e do chamado terceiro setor?

Esse estranhamento encontra explicação no fato de o termo compromisso social estar enraizado na trajetória do ensino superior brasileiro, como bandeira principal da chamada extensão universitária, atividade que, como categoria ética, deveria questionar os rumos do ensino e da pesquisa, desafiando a comunidade universitária para que a universidade como um todo cumpra sua função social (Sampaio, 2004).

Com base em estudos realizados (Calderón, Pessanha e Soares, 2007), defendemos duas hipóteses, na tentativa de separar a função histórica da universidade das influências momentâneas do mercado: apesar de ter ganhado evidência a partir das discussões procedentes do terceiro setor e do mundo empresarial, na década de 1990, o conceito de responsabilidade social não é um conceito estranho ao meio acadêmico, ele faz parte da nossa tradição universitária; e o conceito de responsabilidade social ganha importância e relevância no atual contexto histórico em que primam as políticas educacionais de corte neoliberal e, principalmente, a mercantilização do ensino superior, ao lembrar e exigir o respeito da dimensão pública da educação superior.

A literatura acadêmica aponta que, a partir da segunda metade do século passado, a temática da RSES era assunto de profundo interesse nas universidades europeias (Calderón, 2005). Conforme Santos (1995), naquele período, alguns criticavam o isolamento da universidade e propunham colocá-la 
a serviço da sociedade, outros denunciavam que seu aparente isolamento escondia o envolvimento da universidade em favor dos interesses e das classes dominantes, fato que deveria ser condenado.

As discussões demonstram que a RSES não é um assunto novo no cenário universitário, não é uma temática resultante da influência do mercado e do mundo empresarial. Tampouco é mero compromisso com a questão social, na medida em que se constitui em um dever, isto é, em uma obrigação institucional, parte constitutiva da natureza e da essência da universidade (Calderón, 2005).

Considerando que as discussões em torno da RSES fazem parte da tradição universitária, é válido afirmar que não existe atrito teórico-conceitual com o entendimento do que é a extensão universitária. O conceito de responsabilidade social, juntamente com o conceito de compromisso social, diz respeito às discussões sobre a função social das IES, sobre o seu papel na sociedade brasileira. Já a extensão universitária, juntamente com o ensino e a pesquisa, possibilita que as IES cumpram a sua responsabilidade social, isto é, que atinjam seus objetivos institucionais (Calderón, Pessanha e Soares, 2007).

Existem diversos entendimentos do que seria responsabilidade social (Calderón, Pedro e Vargas, 2011). O mais importante, em termos da gestão universitária, em uma visão mais pragmática, é de ordem legal, pois se parte do pressuposto de que a educação é um direito social e dever do Estado, sendo este o fundamento das instituições educativas (Brasil, 2006b).

Desse princípio, depreende-se, conforme documentos do Ministério da Educação, que todas as IES "têm a responsabilidade de um mandato público para proporcionar aos indivíduos o exercício de um direito social", devendo "prestar contas à sociedade, mediada pelo Estado, do cumprimento de suas responsabilidades, especialmente no que se refere à formação acadêmico-científica, profissional, ética e política dos cidadãos; à produção do conhecimento e promoção do avanço da ciência e da cultura" (Brasil, 2006b, p. 86).

Nessa ótica estatal, a visão predominante é, em sua essência, a "responsabilidade social com a qualidade da educação" (Brasil, 2006c, p. 11). O Estado pretende avaliar "a interação e o cumprimento dos compromissos com a sociedade do ponto de vista da missão educativa" (Brasil, 2006c, p. 22), focando especialmente as contribuições para “a inclusão social, o desenvolvimento econômico e social, a defesa do meio ambiente, a memória cultural, a produção artística e o patrimônio cultural"' (Brasil, 2006a, p.138).

Toda ação que a IES realize, direcionada ao cumprimento da sua missão institucional, na área do ensino e/ou pesquisa, está intimamente associada à sua responsabilidade social, a seu projeto institucional. O norte não é desenvolver projetos assistencialistas ou projetos sociais, como fazem as empresas, mas garantir a qualidade das atividades educacionais que as IES desenvolvem. 
Assim, falar de RSES significa fazer referência ao esforço permanente que as IES devem aplicar para cumprir sua missão. Isso garantirá a boa qualidade de ensino para os cidadãos que buscam formação na graduação ou na pós-graduação.

Trata-se de uma exigência que não se restringe às universidades e aos centros universitários, como é o caso da extensão universitária, mas amplia-se para todas as IES, independentemente de seu porte e natureza jurídica. A RSES envolve deveres e obrigações dessas instituições diante da sociedade que a financia, indo muito mais além de compromissos que muitas vezes deixam de ser assumidos.

Se a RSES diz respeito à qualidade do ensino, convém questionar: qual é o papel do docente na relação de ensino e aprendizagem? Será possível falar de qualidade sem a presença de professores com condições dignas de trabalho e satisfeitos com o ambiente em que interagem?

Apesar das novas teorias que sustentam a chamada sociedade do conhecimento, as quais defendem a responsabilidade do aprendizado no aluno, o autodidatismo (Simão, Santos e Costa, 2003) e a concentração da prática docente na aprendizagem (Masetto, 2005), concordamos com Vasconcelos (2006), quando afirma que a figura do professor deve ser ressaltada como a que imprime sentido à relação ensino-aprendizagem. Nesta, professor e aluno ocupam lugares e papéis já demarcados, aprioristicamente determinados pela instituição que os abriga.

As teorias educacionais e as estratégias didático-metodológicas têm mudado continuamente, mas a importância do professor dificilmente será eliminada no processo ensino-aprendizagem, independentemente do enfoque que seja adotado. A universidade não existe sem professores e sem alunos. Somente os alunos, os computadores e as paredes não geram conhecimento nem conseguem transmitir e transferir conhecimento socialmente útil e relevante.

Práticas como a terceirização de professores por meio de cooperativas fraudulentas, que distorcem os princípios do cooperativismo, não encontram amparo na visão estatal de RSES e vão totalmente contra esse princípio, na medida em que, como demonstraram as pesquisas citadas ao longo deste artigo, essa prática contratual coloca em risco a própria qualidade do ensino.

\section{As cooperativas de mão de obra à luz dos valores do desenvolvimento humano}

Além da visão estatal de RSES, tomamos como referência de análise outra visão difundida no âmbito acadêmico que acena para relacionar a RSES com um novo padrão de desenvolvimento humano. A principal referência teórica são os trabalhos de Morin (2002), para quem o desenvolvimento no 
sentido unicamente técnico e econômico provoca o agravamento tanto da pobreza material dos socialmente excluídos quanto da pobreza da alma e da psiquê.

Morin (2002) acredita que é necessário repensar o desenvolvimento para humanizá-lo, colocando a ética no centro da ideia de desenvolvimento humano, o que significaria integração, combinação e diálogo permanentes entre os processos técnicos e econômicos e as éticas de solidariedade e responsabilidade.

Nessa ótica, Vallaeys (2006), entre outros autores, relaciona a RSES com a convergência da instituição universitária como um todo na promoção de princípios éticos que sustentem uma nova compreensão do desenvolvimento humano.

Em termos mais pragmáticos, a experiência chilena permite entender melhor o que é a RSES. Em documento elaborado por um grupo de universidades desse país, Jimenez de la Jara, Fontecilla e Troncoso afirmam:

Entendemos por responsabilidade social universitária a capacidade que tem a universidade de difundir e colocar em prática um conjunto de princípios e valores gerais e específicos, por meio de quatro processos considerados essenciais, quais sejam, gestão, docência, pesquisa e extensão universitária. Comprometendo-nos, assim, do ponto de vista social, com a própria comunidade universitária e com o país em que se insere (Jimenez de la Jara, Fontecilla e Troncoso, 2006, p. 63).

Nessa visão, se faz referência a princípios e valores direcionados ao desenvolvimento humano que deveriam estar condensados nos projetos pedagógicos e nas diretrizes institucionais que norteiam as IES, incluindo toda a sua estrutura gerencial. Tais princípios e valores podem ser subdivididos em três grandes âmbitos: pessoal (dignidade das pessoas, integridade, honestidade e liberdade); social (bem comum e equidade social, desenvolvimento sustentável, aceitação e valorização da diversidade, sociabilidade e solidariedade, cidadania, democracia e participação); e universitário (excelência acadêmica, compromisso com a verdade, interdependência e transdisciplinaridade).

Analisando-se sob a ótica dos princípios e valores, pode-se abordar a terceirização de professores por meio de cooperativas fraudulentas em dois níveis: o da formação dos alunos e o gerencial. No âmbito da formação dos alunos, convém resgatar a ideia do currículo oculto aplicado à educação superior (Vallaeys, 2006) e questionar: até que ponto existe uma coerência ética entre o que é ensinado em sala de aula e as práticas gerenciais das IES que terceirizam os professores? Que exemplo é dado aos alunos quando se ensina uma teoria que não corresponde à prática institucional da IES onde eles estudam?

A distância entre teoria e prática é abismal. Na teoria, os alunos aprendem ética, cidadania, respeito à lei, aos trabalhadores e aos direitos humanos. 
Na prática institucional, eles aprendem, com o exemplo da própria IES, formas de explorar o trabalhador, de burlar a lei e de evadir impostos.

No âmbito gerencial, se partirmos da premissa de que a RSES se constitui em desafio permanente da gestão universitária, não restam dúvidas de que alcançar o sucesso financeiro da IES torna-se uma exigência para o cumprimento da sua responsabilidade social. Estabelece-se, assim, um círculo no qual se relaciona saúde financeira com investimento em qualidade dentro de princípios éticos que deveriam pautar sua atuação institucional, distante de práticas sustentadas no estelionato acadêmico; na fraude e na enganação em relação aos alunos, parceiros e clientes em potencial; na concorrência desleal e/ou na concorrência ilícita.

Dessa forma, passamos de um cenário essencialmente acadêmico para outro marcado pelo pragmatismo econômico. Trata-se de dois cenários nos quais as IES devem transitar permanentemente para cumprir sua responsabilidade social. Uma IES, como empreendimento saudável, é aquela que consegue estabelecer um diálogo ético e transparente entre as exigências de ambos cenários. Esse diálogo é possível se há clareza da missão institucional e certeza da dimensão pública da educação superior.

Contudo, a mercantilização da educação superior e a ampla disseminação das universidades de massas acabam gerando instituições bipolares que não conseguem estabelecer as conexões que deveriam existir com os cenários acadêmicos e econômicos, como parte da sua responsabilidade social.

\section{Observações finais}

A existência e a proliferação do modelo contratual ilegal, ora analisado, encontram sustentação na omissão do Estado diante da contínua e evidente violação das normatizações estatais, por parte não somente das IES privadas, mas também das estatais. Tal prática não pode ser dimensionada, em termos quantitativos, não somente pela sua própria situação de ilegalidade - uma vez que inexiste um cadastro de IES que contratam professores sob esta modalidade contratual - mas também pela ausência de denúncias por parte dos professores que, ao fazê-lo, perderiam seus postos de trabalho.

Podemos afirmar que ignorar a lei, mais do que burlá-la, tornou-se uma prática rotineira diante da ausência de punições e sanções efetivas, bem como da inexistência de um poder estatal que não somente regule, mas também tenha capacidade de fazer valer as regras de funcionamento do sistema de educação superior.

Desta forma, identificamos um dos principais problemas da área das políticas públicas: a falta de continuidade ou a ruptura na continuidade das políticas educacionais em decorrência das mudanças de governo. 
Os dados apresentados sobre a terceirização de professores no ensino superior privado, que enfatizam o elevado grau de insatisfação docente e o acentuado risco de descompromisso dos professores na relação ensino-aprendizagem, nos remetem ao texto de Leite (1980) As sete pragas da universidade brasileira. Esse clássico trouxe, para o contexto das universidades, uma discussão acerca das problemáticas que envolvem o dia a dia das IES. Passaram-se trinta anos desde a primeira edição e as pragas, conforme o próprio autor, ainda permanecem latentes no cenário educacional (Leite, 2000).

A primeira praga, segundo Leite, seria a prática do regime de tempo parcial/horista, que obriga o professor a atuar em diversas instituições, não dispondo de tempo para atualizar-se, tornando-se

(...) professor-caixeiro-viajante que, desnutrido física e intelectualmente, ganha seu pão itinerantemente, em diferentes cidades às vezes, sem tempo de se atualizar e de se dedicar, minimamente que seja à pesquisa e reflexão; verdadeiros Zumbis vomitando conhecimentos obsoletos e, frequentemente, errôneos ou viciados (Leite, 1980, p. 16).

As outras seis pragas localizam-se em diversos cenários da cultura universitária. Referem-se ao conformismo nas instituições estatais diante da estabilidade de emprego, ao isolacionismo do mundo acadêmico, à burocracia, à falta de diálogo efetivo entre os diferentes setores da universidade e o fechamento dos mesmos em submundos, à falta de autonomia e ao gigantismo alcançado que, muitas vezes, não possuem o devido suporte administrativo e pedagógico.

A discussão levantada aqui articula-se com a primeira praga, isto é, a prática do regime de tempo parcial/horista, cujos efeitos negativos são potencializados na contratação por meio de cooperativas de mão de obra, com repercussões na autoestima do professor, em sua dignidade como trabalhador, já que não tem nenhum benefício social reconhecido, nem amparo na legislação trabalhista e, principalmente, não se sente incluído no mercado formal de trabalho.

Trata-se de um sistema contratual considerado pelos próprios professores entrevistados nas pesquisas citadas como "modelo escravista", realizado por meio de 'cooper-fraudes', "empreiteiras de mão de obra", que visam à "exploração profissional".

Todos esses motivos permitem visualizar, na terceirização de professores por meio de cooperativas, uma oitava praga da educação superior, que vem se expandindo principalmente na Região Sudeste do país. Tal prática, que vem sendo reprimida pela atuação da Justiça do Trabalho, do Ministério Público do Trabalho e dos sindicatos de professores, além de ir contra 
a dignidade do trabalhador, coloca em risco a qualidade das atividades educacionais, colidindo com as duas visões de RSES aqui analisadas.

Finalmente, este artigo permite refletir sobre a importância da organização docente diante de práticas gerenciais que atingem diretamente a dignidade do profissional da educação. Nesse sentido, as reflexões de Paulo Freire continuam atuais e relevantes, quando afirma que:

(...) a luta dos professores em defesa de seus direitos e de sua dignidade deve ser entendida como um momento importante de sua prática docente, enquanto prática ética. Não é algo que vem de fora da atividade docente, mas algo que dela faz parte. O combate em favor da dignidade da prática docente é tão parte dela mesma quanto dela faz o respeito que o professor deve ter à identidade do educando, à sua pessoa, a seu direito de ser (Freire, 1996, p. 74).

Nessa perspectiva, ganha destaque o exercício da docência e a contínua busca pela dignidade dos profissionais da educação, dois processos que estão profundamente entrelaçados e que, por questões éticas, não podem ser separados.

Como pode ser observado, a concepção freireana do exercício da docência colide com qualquer visão meramente romântica que relaciona o exercício da docência a uma missão divina ou a uma mera abnegação, apesar das adversidades. Para além de qualquer visão romântica, o exercício da docência possui uma dimensão coletiva que se concretiza na prática da defesa da dignidade profissional, bem como uma dimensão individual, que ganha concretude na responsabilidade ética existente na relação professor-aluno.

É nessa tensão, entre as dimensões individual e coletiva, que a práxis educacional se debruça de forma contínua e permanente, correndo o risco de um desequilíbrio que acena para extremos. Por um lado, está um coletivismo corporativista irracional, próprio de muitos sindicatos marcados pelo burocratismo e a corrupção, e por outro, um ceticismo individualista, que isola o educador da sua condição de trabalhador da educação, impedindo-o de ver alternativas além do seu próprio mundo. É precisamente entre esses extremos que o docente se insere, digladiando continuamente para conquistar sua dignidade profissional, muitas vezes roubada pelos empresários da educação. 


\section{Notas}

1 Pontifícia Universidade Católica de Campinas, Campinas, São Paulo, Brasil.

Doutor em Ciências Sociais pela Pontifícia Universidade Católica de São Paulo e pós-doutor em Ciências da Educação pela Universidade de Coimbra, Portugal.

<adolfo.ignacio@puc-campinas.edu.br>

Correspondência: PUC-Campinas, Nupex/CCHSA, Rodovia Dom Pedro I, Km 36, Parque das Universidades, CEP 13086-900, Campinas, São Paulo, Brasil.

2 Artigo inédito, sem financiamento ou conflito de interesses, resulta de duas pesquisas: "Flexibilização e terceirização do trabalho docente no ensino superior privado", realizada com financiamento da Fundação de Amparo ao Ensino e Pesquisa (FAEP); e "Responsabilidade social da educação superior: levantamento, análise e avaliação do conhecimento acadêmico produzido no Brasil (2004-2010)", desenvolvida no Programa de Mestrado em Educação da PUC-Campinas. Ambas pesquisas contaram com o apoio do Conselho Nacional de Desenvolvimento Científico e Tecnológico (CNPq).

3 Os depoimentos analisados neste artigo resultaram das entrevistas realizadas com dez professores universitários que atuavam em instituições de educação superior em regime de terceirização por meio de cooperativas de mão de obra - quatro professores especialistas, três mestres e três doutores (Calderón et al., 2008b).

\section{Referências}

BRASIL. Ministério da Educação. Instituto Nacional de Estudos e Pesquisas Educacionais Anísio Teixeira. Lei n. 10.861, de 14 de abril de 2004. Institui o Sistema Nacional de Avaliação da Educação Superior-Sinaes e dá outras providências. Sistema Nacional de Avaliação da Educação Superior: da concepção à regulamentação. Brasília: Inep, 2006a.

. Ministério da Educação. Instituto Nacional de Estudos e Pesquisas Educacionais Anísio Teixeira. Sistema Nacional de Avaliação da Educação Superior: da concepção à regulamentação. Brasília: Inep, 2006b.

. Ministério da Educação. Comissão Nacional de Avaliação de Educação Superior. Instituto Nacional de Estudos e Pesquisas Educacionais Anísio Teixeira. Avaliação externa das instituições de educação superior. Brasília: Inep, 2006c.
CALDERÓN, Adolfo I. Responsabilidade social: desafios à gestão universitária. Revista Estudos, Brasília, n. 34, p. 13-27, 2005.

CALDERÓN, Adolfo I. et al. Terceirização na educação superior: o trabalho do docente por meio de cooperativas de mão-de-obra. Eccos: Revista Científica, São Paulo, v. 10, n. 1/2, p. 189-212, jan./jun. 2008a.

CALDERÓN, Adolfo I. et al. Educação superior: o sindicalismo e as cooperativas de professores. Universidade e Sociedade, Brasília, ano XVIII, n. 42, p. 149-159, jun. 2008b.

CALDERÓN, Adolfo I. et al. Educação superior: O exercício da função docente por meio de cooperativas de mão-de-obra. In: REUNIÃO ANUAL DA ANPED, 31., 2008, Caxambu, Anais... Rio de Janeiro: Anped, 2008c. 1 CD-ROM. 
CALDERÓN, Adolfo I.; LOURENCO, Henrique da S. Ensino superior privado: expansão das cooperativas de mão de obra docente. Cadernos de Pesquisa, São Paulo, v. 41, n. 143, p. 642-659, 2011.

CALDERÓN, Adolfo I.; PEDRO, Rodrigo F.; VARGAS, Maria C. Responsabilidade social da educação superior: a metamorfose do discurso da Unesco em foco. Interface: Comunicação, Saúde, Educação, Botucatu, v. 15, n. 39, p. 1185-1198, out./dez. 2011.

CALDERÓN, Adolfo I.; PESSANHA, Jorge; SOARES, Vera L. Educação superior: construindo a extensão nas IES particulares. São Paulo: Xamã, 2007.

FERREIRA, Naura S. C. Por uma extensão universitária solidária, fraterna e humana. In: CALDERÓN, Adolfo I. Educação superior: construindo a extensão universitária nas IES particulares. São Paulo: Xamã, 2007. p. 9-10.

FREIRE, Paulo. Pedagogia da autonomia: saberes necessários à prática educativa. São Paulo: Paz e Terra, 1996.

JIMÉNEZ DE LA JARA, Mónica; FONTECILLA, José M.; TRONCOSO, Catalina D. Responsabilidade universitária: uma experiência inovadora na América Latina. Revista Estudos, Brasília, ano 24, n. 36, p. 57-73, mar. 2006.

LEITE, Rogério C. As sete pragas da universidade. 2. ed. São Paulo: Duas Cidades, 1980.

As sete pragas da universidade revisitadas. Folha de S. Paulo, São Paulo, 1 out. 2000. Caderno Opinião, p. 2.

MARX, Karl. O capital. São Paulo: Editora Nova Cultural, 1996. (Coleção Os Economistas, v. 1).

MASETTO, Marcos. Docência universitária: repensando a aula. In: TEODORO, António; VASCONCELOS, Maria L. (Org.). Ensinar e aprender no ensino superior: por uma epistemologia da curiosidade na formação universitária. São Paulo: Editora Mackenzie; Cortez, 2005. p. 79-108.

MORIN, Edgar. Estamos en un Titanic?. In: BERNARDO Kliksberg. Ética y desarrollo, la relación marginada. Buenos Aires: El Ateneo, 2002. p. 143-148.

SAMPAIO, Jorge H. Política nacional de extensão: referenciais teórico-práticos para sua construção. In: CALDERÓN, Adolfo I. (Org.). Ação comunitária: uma outra face do ensino superior brasileiro. São Paulo: Olho d’Água, 2004. p. 13-25.

SANTOS, Boaventura de S. Pela mão de Alice: o social e o político na pós-modernidade. São Paulo: Cortez, 1995.

SIMÃO, José V.; SANTOS, Sérgio; COSTA, António. Ensino superior: uma visão para a próxima década. Aveiro: Universidade, 2003. 519p.

TAKAHASHI, Fábio. Em crise, escolas terceirizam professor. Folha de S. Paulo, 27 nov. 2006. Disponível em: <wwwl.folha.uol.com. br/folha/educacao/ult305u 19139.shtml>. Acesso em: 27 jan. 2012.

UNESCO. Educação: um tesouro a descobrir. Comissão Internacional sobre Educação para o século XXI. Relatório. São Paulo: Cortez; Brasília: MEC; Unesco, 2001. 288p.

VALLAEYS, François. Que significa responsabilidade social universitária?. Revista Estudos, Brasília, ano 24, n. 36, p. 35-55, jun. 2006.

VASCONCELOS, Maria L. Autoridade docente no ensino superior: discussões e encaminhamentos. São Paulo: Xamã; Niterói: Intertexto, 2006.

Recebido em 27/02/2012

Aprovado em 04/11/2012 